\title{
Early onset airway obstruction in response to organic dust in the horse
}

\author{
Christopher M. Deaton, ${ }^{1}$ Laura Deaton, ${ }^{1}$ Eduard Jose-Cunilleras, ${ }^{1}$ \\ Thea L. Vincent, ${ }^{2}$ Alan W. Baird, ${ }^{3}$ K. Dacre, ${ }^{4}$ and David J. Marlin ${ }^{1}$ \\ ${ }^{1}$ Department of Physiology, Animal Health Trust, Kentford, United Kingdom; ${ }^{2}$ Hartpury College, \\ Hartpury, Gloucester, United Kingdom; ${ }^{3}$ School of Agriculture, Food Science and Veterinary Medicine, \\ University College Dublin, Dublin, Ireland; ${ }^{4}$ Department of Veterinary Clinical Sciences, \\ Royal (Dick) School of Veterinary Studies, Easter Bush, Midlothian, United Kingdom
}

Submitted 1 March 2006; accepted in final form 12 October 2006

\begin{abstract}
Deaton CM, Deaton L, Jose-Cunilleras E, Vincent TL, Baird AW, Dacre K, Marlin DJ. Early onset airway obstruction in response to organic dust in the horse. J Appl Physiol 102: 1071-1077, 2007. First published December 7, 2006; doi:10.1152/japplphysiol.00264.2006.Equine recurrent airway obstruction (RAO) has been used as a naturally occurring model of human asthma. However, it is unknown whether there is an early-phase response in RAO. The aim of this study was to determine whether exposure to organic dust induces immediate changes in lung function in RAO-affected horses, which could be mediated by airway mast cells. Six RAO-affected horses in remission and six control horses were challenged with hay-straw dust suspension by nebulization. Total respiratory resistance at $1 \mathrm{~Hz}$, measured by forced oscillation, was increased from $0.62 \pm 0.09 \mathrm{cmH}_{2} \mathrm{O} \cdot 1^{-1} \cdot \mathrm{s}$ (mean $\pm \mathrm{SE}$ ) to $1.23 \pm 0.20 \mathrm{cmH}_{2} \mathrm{O} \cdot 1^{-1} \cdot \mathrm{s} 15 \mathrm{~min}$ after nebulization in control horses $(P=0.023)$ but did not change significantly in the RAO group. Total respiratory reactance at $1 \mathrm{~Hz}(P=0.005)$ was significantly lower in the control horses $\left(-0.77 \pm 0.07 \mathrm{cmH}_{2} \mathrm{O} \cdot 1^{-1} \cdot \mathrm{s}\right)$ than in the RAO group $\left(-0.49 \pm 0.04 \mathrm{cmH}_{2} \mathrm{O} \cdot 1^{-1} \cdot \mathrm{s}\right) 15 \mathrm{~min}$ after nebulization. Bronchoalveolar lavage fluid (BALF) histamine concentration was significantly elevated 10 and $20 \mathrm{~min}$ postnebulization in control horses but not in RAO horses. Minimum reactance at $1 \mathrm{~Hz}$ in the early postnebulization period significantly correlated with both prechallenge BALF mast cell numbers $(r=-0.65, P=0.02)$ and peak BALF histamine concentration postnebulization $(r=-0.61, P=$ 0.04). In conclusion, RAO horses, unlike human asthmatic patients, do not exhibit an early-phase response. However, healthy control horses do demonstrate a mild but significant early ( $<20 \mathrm{~min})$ phase response to inhaled organic dust. This response may serve to decrease the subsequent dose of dust inhaled and as such provide a protective mechanism, which may be compromised in RAO horses.
\end{abstract}

equine; lung function; allergen

HUMAN ASTHMATIC PATIENTS develop an early-phase bronchoconstriction within minutes of exposure to inhaled allergens. Subsequently, a late asthmatic response with the continuation of airway obstruction and the development of airway inflammation can also be observed. Mast cells play an important role in the early asthmatic response in both atopic and nonatopic human asthma $(9,42)$. Allergen can activate mast cells by cross-linking to high-affinity IgE receptors (FceRI) (40). The activation of mast cells in response to inhaled allergen results in the release of mast cell mediators, including histamine, tryptase, chymase, cysteinyl leukotrienes, and prostaglandin $\mathrm{D}_{2}(8,14)$. These mediators can induce airway smooth muscle contraction and the observed early-phase asthmatic response $(8,14)$. Mast cells also release proinflammatory cytokines that,

Address for reprint requests and other correspondence: C. M. Deaton, Dept of Physiology, Animal Health Trust, Lanwades Park, Kentford, Suffolk CB8 7UU, UK. together with other mast cell mediators, have the potential to induce neutrophil and eosinophil infiltration and bronchoconstriction involved in the late-phase asthmatic response $(4,8$, 14). Activation of other mast cell receptors, in addition to FceRI, such as KIT and complement component 3a receptor, can also induce mast cell degranulation or amplify FceRImediated mast cell activation $(1,3,16,21)$.

Recurrent airway obstruction (RAO) is an equine inflammatory airways disease characterized by the development of a late-phase response after exposure to organic dust, typically from hay and straw. The late-phase response comprises airway obstruction, airway inflammation, and airway hyperreactivity. RAO has been suggested to be the most similar naturally occurring disease in animals to human asthma (35) and has been used as model of human asthma $(2,6,17,39)$.

Few studies have investigated the role of mast cells in the pathogenesis of RAO. The degranulation of basophilic blood cells and pulmonary mast cells in vitro in response to mold spores has been demonstrated to be greater in cells derived from RAO-affected horses than in those derived from control horses $(13,19)$. Exposure to hay and straw for $5 \mathrm{~h}$ increased the concentration of histamine in bronchoalveolar lavage (BAL) fluid (BALF) in RAO-affected horses but not in control horses (26). In contrast, a 30-min exposure to hay and straw did not result in a significant increase in BALF histamine concentration (26). However, histaminase activity in the lung (22) may have resulted in the degradation of histamine released during an early-phase response by the time the 30-min sample was collected. Mast cells that contain chymase rather than tryptase appear to play a role in RAO, with the number of chymasepositive mast cells correlating with the severity of neutrophil infiltration (41). Mediators that are released from mast cells, but not activated neutrophils, have been implicated in the induction of bronchoconstriction in RAO (28). Levels of $\operatorname{IgE}$ antibodies in response to mold allergens were greater in BALF from RAO horses when in remission, as well as from those demonstrating clinical signs of disease, compared with BALF from healthy horses $(18,33)$. Enhanced production of IL-4 and IL-13 may elevate allergen-specific IgE generation from B cells during the early stages of RAO (20). IgE-mediated reactions do not appear to be important in the late-phase response in RAO (41).

The duration of organic dust exposure required before RAOaffected horses develop clinical evidence of airway obstruction varies from hours to days $(15,33)$, and clinical evidence of an

The costs of publication of this article were defrayed in part by the payment of page charges. The article must therefore be hereby marked "advertisement" in accordance with 18 U.S.C. Section 1734 solely to indicate this fact. 
early/immediate obstructive response is not apparent. However, the presence of a subclinical early response has not been investigated. If a subclinical early-phase response to inhaled dust does occur in RAO, the proinflammatory mediators released could exacerbate the late-phase response observed in RAO $(12,23)$. Therefore, modulating or blocking an earlyphase response could be an important therapeutic opportunity. We hypothesized that RAO-affected horses undergo an earlyphase subclinical airway obstruction mediated by mast cells when exposed to organic dust. The aims of the study were to determine whether an early-phase response to nebulized organic dust challenge occurs in RAO and whether the magnitude of an early-phase response is related to the late-phase inflammatory response.

\section{MATERIALS AND METHODS}

The experimental protocol was approved by the Ethical Review Committee of the Animal Health Trust and conformed to the Home Office Animals (Scientific Procedures) Act 1986.

Animals. Six RAO-affected horses [4 geldings, 2 mares; mean age $14 \pm 0.7( \pm \mathrm{SE}) \mathrm{yr}$ and $510 \pm 12 \mathrm{~kg}$ body wt] and six control horses ( 4 geldings, 2 mares; mean age $11 \pm 0.8 \mathrm{yr}$ and $447 \pm 22 \mathrm{~kg}$ body wt) were studied after between 15 and $20 \mathrm{wk}$ at pasture. Exposure to organic dust, by stabling with hay and straw, had previously been demonstrated to induce reversible lung dysfunction in the RAO group (increase in respiratory resistance from $0.73 \pm 0.06$ to $1.47 \pm 0.12$ $\mathrm{cmH}_{2} \mathrm{O} \cdot 1^{-1} \cdot \mathrm{s}$ ) but not the control horses (from $0.67 \pm 0.06$ to $0.66 \pm$ $\left.0.06 \mathrm{cmH}_{2} \mathrm{O} \cdot 1^{-1} \cdot \mathrm{s}\right)$.

Study protocol. To control the dose of organic dust that each animal received, horses were nebulized with a hay-straw dust suspension (29) rather than exposed to hay and straw directly in a stable. Horses were sedated 7 min before nebulization of hay-straw dust suspension. Two minutes before nebulization ( $5 \mathrm{~min}$ after sedation), pulmonary function was measured. Horses were nebulized for $2 \mathrm{~min}$ with hay-straw dust suspension. Five and 15 min after the end of nebulization (14 and 24 min after sedation, respectively), pulmonary function tests were repeated. Ten minutes after the end of nebulization, BAL was performed in either the right or left lung. Twenty minutes after nebulization, BAL was performed in the contralateral lung. Seven days before nebulization, pulmonary function tests and BAL were performed at the same time points as described above without nebulization, to take into account any effects of sedation and BAL on lung function and to determine baseline values of lung function, BALF cytology, and histamine concentration. Twenty-four hours after nebulization, pulmonary function tests and BAL were performed $5 \mathrm{~min}$ after sedation. BAL was performed in an adjacent lung segment to that lavaged previously.

Horses were sedated intravenously with romifidine $(40 \mu \mathrm{g} / \mathrm{kg}$ body wt; Sedivet, Boehringer Ingelheim, Bracknell, UK) and butorphanol (20 $\mu \mathrm{g} / \mathrm{kg}$ body wt; Torbugesic, Fort Dodge Animal Health, Southampton, UK). Lung function was assessed by measuring total respiratory resistance and reactance at $1.0,2.0,3.0$, and $5.0 \mathrm{~Hz}$ by forced oscillatory mechanics (11). BAL was performed by instilling $500 \mathrm{ml}$ of $0.9 \%$ saline at $37^{\circ} \mathrm{C}$ as described previously (10) but without local anesthesia of the conducting airways. BALF nucleated cell counts were determined manually on a hemocytometer. BALF differential cell counts were determined manually on cytospin preparations, which were made within 15 min of collection, and stained with hematoxylin and eosin. We have previously demonstrated that there is good agreement in the mast cell percentages measured in BALF when staining with hematoxylin and eosin $(5.0 \pm 0.8 \%)$ compared with Leishman's stain $(5.3 \pm 0.8 \%)$ in six control horses and six RAO horses (unpublished observations). For histamine analysis, BALF was stored on ice before centrifugation at $1,000 \mathrm{~g}$ for 10 min at $4{ }^{\circ} \mathrm{C}$ within $15 \mathrm{~min}$ of collection. BALF supernatant was stored at $-80^{\circ} \mathrm{C}$ until analysis. The concentration of histamine in BALF supernatant was analyzed by ELISA (kit no. 59221; IBL ImmunoBiological Laboratories, Hamburg, Germany).

Nebulization of hay-straw dust suspension. The hay-straw dust suspension was produced as described previously (32) from batches of hay and straw that had been demonstrated to induce airway obstruction in the group of RAO-affected horses, but not the control horses, utilized in the present study. Two milliliters of hay-straw dust suspension $(100 \mathrm{mg} / \mathrm{ml}$ saline) were aerosolized with the use of a jet nebulizer (Sidestream, Profile Respiratory Systems, Bognor Regis, West Sussex, UK) and compressor (Corning, Halstead, Essex, UK), with a calibrated output of $6 \mathrm{1} / \mathrm{min}$ (29). The aerosol generated was transmitted into the inspiratory airflow of the horse via a closed delivery system for $2 \mathrm{~min}$ at a nebulization rate of $0.5 \mathrm{ml} / \mathrm{min}$.

Statistical analyses. Variables that were not normally distributed as assessed by the Shapiro-Wilk's normality test were transformed by the natural logarithm, and the Shapiro-Wilk's test was reapplied. This approach resulted in the data sets approximating a normal distribution. The effects of sedation and BAL on lung function tests and differences in cytology and histamine concentration in BALF collected from the left and right lung seven days before nebulization were investigated by one-way ANOVA. Measures of pulmonary function were not affected by either sedation or BAL. Therefore, the effect of organic dust nebulization on pulmonary function was assessed by comparing data collected $5 \mathrm{~min}, 10 \mathrm{~min}$, and $24 \mathrm{~h}$ after nebulization with that measured $2 \mathrm{~min}$ before nebulization. Similarly, because there were no differences between measures in left and right BALF collected 7 days before nebulization, the two sets of data were pooled and presented as the prenebulization baseline BALF data.

A nested ANOVA for repeated measures (repeated, replicated two-way ANOVA) was used to determine the significance of the effect of nebulization and differences between the RAO and control groups. If significance was attained, further analyses were performed with Tukey's test for multiple comparisons. Correlations were investigated by Spearman's Rank test. Results were considered to be significant at $P<0.05$. Data are presented as means \pm SE. Statistical analyses were performed with StatMost for Windows (DataMost, Salt Lake City, UT).

\section{RESULTS}

BALF cytology. BALF cytology was not significantly altered 10 or 20 min after challenge with organic dust in RAO-affected horses (Table 1). In the control group, BALF lymphocyte counts were decreased $10 \mathrm{~min}$ postnebulization $(P=0.016)$, and BALF total nucleated cell counts and macrophage counts were decreased $10 \mathrm{~min}(P=0.003$ and $P=0.007$, respectively) and $20 \mathrm{~min}(P=0.022$ and $P=0.020$, respectively) postnebulization and returned to baseline values within $24 \mathrm{~h}$ (Table 1). Twenty-four hours after nebulization, BALF neutrophil counts were significantly higher than before nebulization in the RAO group $(P<0.0001)$ but not in the control group (Table 1).

$B A L F$ histamine concentration. In the control group, the concentration of histamine in BALF was higher $10 \mathrm{~min}(P=$ $0.027)$ and $20 \mathrm{~min}(P=0.036)$ after nebulization compared with prenebulization (Fig. 1). BALF histamine concentration was not significantly altered after nebulization in the RAO group (Fig. 1).

Pulmonary function. Neither total respiratory resistance nor reactance at $1,2,3$, or $5 \mathrm{~Hz}$ was significantly changed by organic dust nebulization in the RAO group (Figs. 2 and 3$)$. Total respiratory resistance at $1 \mathrm{~Hz}(P=0.023)$ and $2 \mathrm{~Hz}(P=$ $0.05)$ was increased 15 min after nebulization in control horses (Fig. 2). Total respiratory resistance at 3 and $5 \mathrm{~Hz}$ was not 
Table 1. Bronchoalveolar lavage fluid cytology in control horses and horses affected by RAO before and after nebulization of organic dust

\begin{tabular}{|c|c|c|c|c|}
\hline & \multicolumn{4}{|c|}{ Time After Nebulization } \\
\hline \multicolumn{5}{|c|}{ Total nucleated cell count, number/ $\mu \mathrm{l}$} \\
\hline RAO & $280 \pm 83$ & $283 \pm 111$ & $163 \pm 46$ & $523 \pm 232$ \\
\hline \multicolumn{5}{|c|}{ Macrophage, $\%$} \\
\hline Control & $53 \pm 6$ & $52 \pm 7$ & $49 \pm 12$ & $50 \pm 13$ \\
\hline RAO & $49 \pm 8$ & $53 \pm 8$ & $45 \pm 5$ & $34 \pm 11$ \\
\hline RAO & $44 \pm 8$ & $42 \pm 8$ & $49 \pm 5$ & $37 \pm 12$ \\
\hline \multicolumn{5}{|c|}{ Neutrophil, \% } \\
\hline Control & $2 \pm 2$ & $2 \pm 1$ & $3 \pm 2$ & $6 \pm 6$ \\
\hline RAO & $2 \pm 2$ & $2 \pm 2$ & $3 \pm 2$ & $26 \pm 11 * \dagger$ \\
\hline \multicolumn{5}{|c|}{ Mast cell, \% } \\
\hline Control & $6 \pm 2$ & $6 \pm 5$ & $6 \pm 5$ & $4 \pm 3$ \\
\hline RAO & $4 \pm 2$ & $3 \pm 2$ & $3 \pm 3$ & $2 \pm 1$ \\
\hline Control & $110 \pm 15$ & $47 \pm 10 *$ & $60 \pm 12$ & $151 \pm 28$ \\
\hline RAO & $127 \pm 42$ & $117 \pm 46$ & $82 \pm 26$ & $186 \pm 70$ \\
\hline \multicolumn{5}{|c|}{ Neutrophil count, number/ $\mu 1$} \\
\hline Control & $6 \pm 1$ & $2 \pm 1$ & $4 \pm 1$ & $20 \pm 7$ \\
\hline RAO & $4 \pm 1$ & $4 \pm 2$ & $4 \pm 1$ & $181 \pm 114 *$ \\
\hline \multicolumn{5}{|c|}{ Mast cell count, number/ $\mu 1$} \\
\hline Control & $14 \pm 1$ & $8 \pm 3$ & $10 \pm 4$ & $11 \pm 6$ \\
\hline RAO & $9 \pm 2$ & $7 \pm 2$ & $4 \pm 1$ & $7 \pm 2$ \\
\hline
\end{tabular}

Values are means \pm SE. RAO, recurrent airway obstruction. *Significantly different compared with prenebulization (Pre) $(P \leq 0.02) . \dagger$ Significantly different compared with control horses $(P=0.003)$.

changed after nebulization in control horses (Fig. 2). Total respiratory reactance at $1 \mathrm{~Hz}(P=0.005)$ and $2 \mathrm{~Hz}(P=0.03)$ was significantly lower in the control horses than in the RAO group 15 min after nebulization (Fig. 3). Reactance at $3 \mathrm{~Hz}$ was lower 5 and 15 min postnebulization compared with prenebulization in the control group $(P=0.035$ and $P=0.015$, respectively; Fig. 3). Resonant frequency was not altered by organic dust nebulization in the RAO group (Fig. 4). In the control group, resonant frequency was significantly increased 15 min postnebulization compared with before nebulization $(P=0.025)$ and $24 \mathrm{~h}$ postnebulization $(P=0.009)$ (Fig. 4$)$.

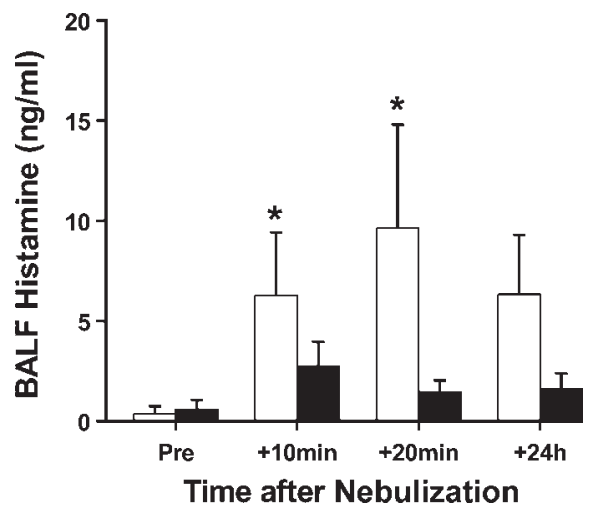

Fig. 1. Concentration of histamine in bronchoalveolar lavage fluid (BALF) from control horses ( $n=6$; open bars) and horses affected by recurrent airway obstruction ( $n=6$; closed bars) before (Pre) and after nebulization of organic dust. Data are means \pm SE. *Significantly different compared with Pre $(P \leq$ $0.04)$.
Correlations. The most negative reactance at $1 \mathrm{~Hz}$ measured at either 5 or 15 min after nebulization for each horse correlated inversely with the BALF mast cell number before nebulization ( $r=-0.65, P=0.02$; Fig. 5), and the peak BALF histamine concentration 10 or $20 \mathrm{~min}$ after nebulization $(r=$ $-0.61, P=0.04)$. BALF mast cell number prenebulization also correlated with peak BALF histamine concentration postnebulization $(r=0.89, P=0.0001)$. BALF neutrophil number $24 \mathrm{~h}$ postnebulization was not correlated with BALF mast cell number before exposure, peak BALF histamine concentration 10 or 20 min postnebulization, or total respiratory reactance or resistance 5 or $15 \mathrm{~min}$ after nebulization.

\section{DISCUSSION}

In contrast to our hypothesis, an early-phase response to organic dust consisting of decreased lung function and increased BALF histamine concentration was identified in control horses rather than in the RAO group. The results also differ from studies in human subjects, where asthmatic but not nonasthmatic individuals demonstrate an early-phase response to inhaled allergen.

The study design included sedation before nebulization of the organic dust. This procedure may have decreased the effects of organic dust on lung function. The measurements taken before nebulization were performed not only to determine baseline lung function but also to account for any effects of sedation and the procedure of BAL on lung function. In the control horses and RAO-affected horses in remission before nebulization, sedation and BAL did not result in significant 
Fig. 2. Total respiratory resistance in control horses ( $n=6$; open bars) and horses affected by recurrent airway obstruction ( $n=6$; closed bars) before (Pre) and after nebulization of organic dust. Data are means \pm SE. *Significantly different compared with Pre and $24 \mathrm{~h}$ post $(P \leq$ $0.05)$.
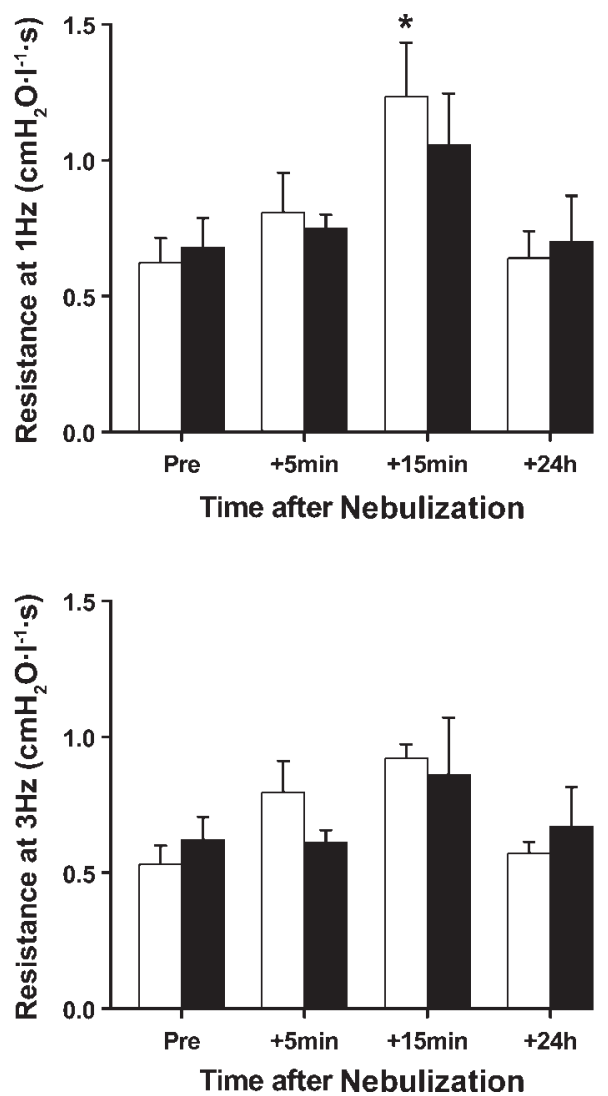
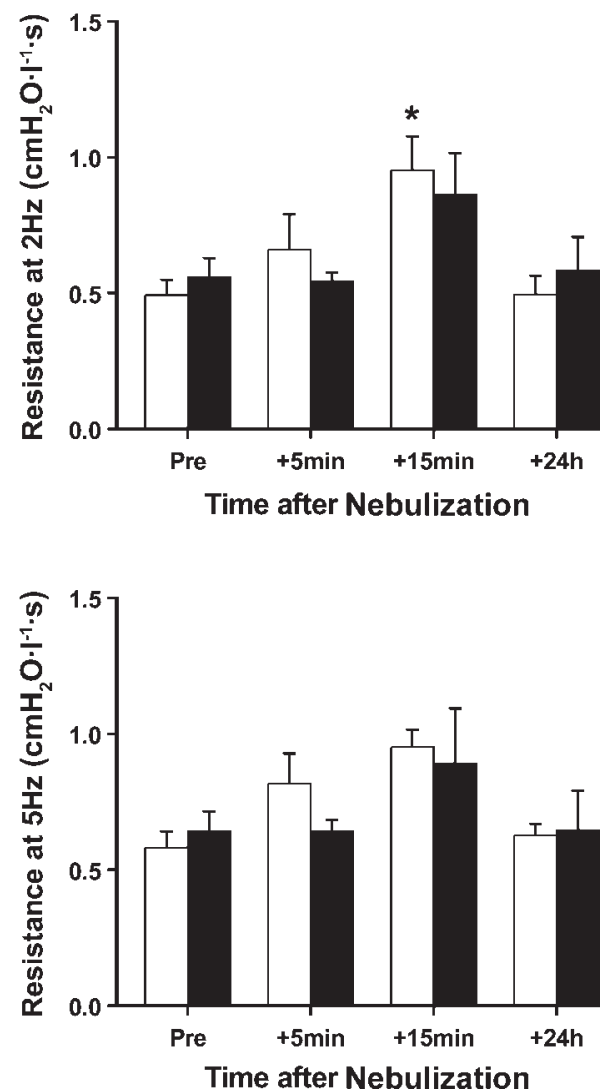

changes in lung function at the time points measured. However, in RAO-affected horses with airway obstruction, sedation with $\alpha_{2}$-agonists has been demonstrated to decrease airway resistance $(5)$.

The technique of forced oscillation was used to measure lung function instead of simultaneous measures of transpulmonary pressure and flow rate, as the forced oscillation technique is noninvasive and can identify frequency-dependent changes (44). Lung function measurements with the two techniques have previously been demonstrated to closely correlate (43). The forced oscillation technique not only measures the reactance and resistance of peripheral intrathoracic airways but also of extrathoracic airways, including the larynx. Alterations in lung function measured in control horses after nebulization may therefore not be a result of small airway obstruction. However, the observations of 1 ) a negative frequency dependence in total respiratory resistance and 2) a more negative reactance at frequencies below resonant frequency in control horses $15 \mathrm{~min}$ postnebulization are consistent with distal small airway obstruction rather than upper airway obstruction in humans (34). Saline nebulization was not used as a control. However, we have previously determined that lung function is not altered up to $10 \mathrm{~min}$ after saline nebulization in either control or RAO horses (Deaton and Marlin, unpublished observations).

Despite the measurement of statistically significant decreases in lung function in the control group after organic dust nebulization, no clinical signs of increased respiratory effort (such as increased respiratory rate, abdominal effort, or nasal flaring) were observed, suggesting that the degree of airway obstruction was mild. It is plausible that the early-phase re- sponse of the control horses may be a protective mechanism. In healthy human subjects, the induction of bronchoconstriction before inhalation of Teflon particles significantly reduced the fraction of particles deposited in the peripheral airways and alveoli (36). Furthermore, the fraction of particles deposited in the peripheral airways and alveoli was considerably diminished by only a relatively small degree of bronchoconstriction (36). Therefore, in control horses, after a mild early-phase airway obstruction, the subsequent dose of inhaled organic dust reaching the alveoli would be decreased, which would reduce the stimulus for the late-phase response. The absence of a significant early-phase response in RAO-affected horses would conversely render them more susceptible to higher dust deposition in the alveoli and peripheral airways and consequently result in an exaggerated late-phase response. The deficiency of a significant early-phase response in RAO horses may reflect the absence of sufficient numbers of pulmonary mast cells to produce adequate amounts of mediators to induce airway smooth muscle contraction. Combining data from both the control and RAO groups, decrements in lung function measured during the early phase were associated with the BALF histamine concentration and BALF mast cell number. Mast cells can release a range of mediators in addition to histamine, such as 5-hydroxytryptamine and leukotriene $\mathrm{D}_{4}$, which are also able to enhance airway smooth muscle contraction in the horse by augmenting cholinergic responses (28).

The decrease in lung function observed in the control horses may not solely be explained by airway smooth muscle contraction. In human asthmatic patients, local allergen rapidly induced hyperemia, edema, and bronchial narrowing (27). In a guinea pig model of human asthma, increased mucous secre- 

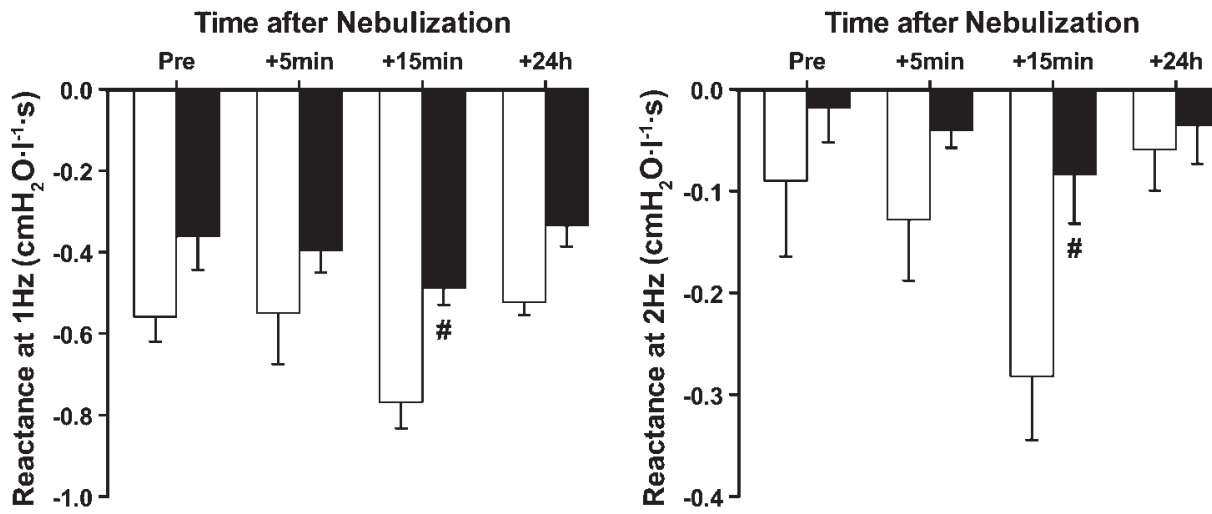

Fig. 3. Total respiratory reactance in control horses ( $n=6$; open bars) and horses affected by recurrent airway obstruction $(n=6$; closed bars $)$ before (Pre) and after nebulization of organic dust. Data are means \pm SE. *Significantly different compared with Pre and $24 \mathrm{~h}$ post $(P \leq$ 0.04). \#Significantly different compared with
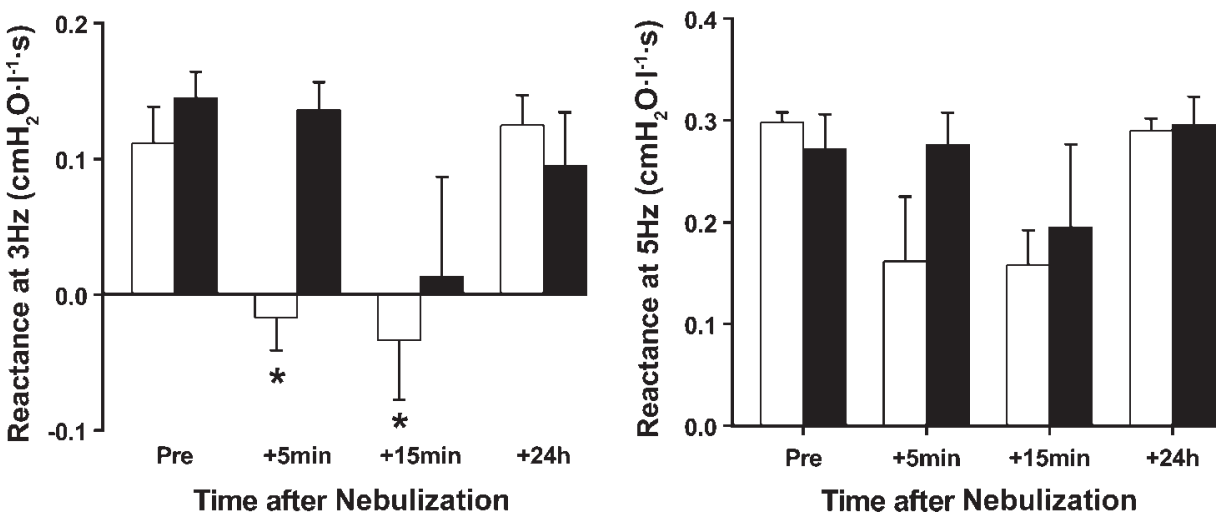
control horses $(P \leq 0.03)$.

tion and pulmonary edema occurred immediately after exposure to allergen in sensitized animals (38). Pulmonary edema appeared to reflect airway epithelial cell disruption induced by inflammatory cells (38). In the present study, there was no evidence for mucous accumulation or inflammatory cell infiltration into the airways in control horses after nebulization of organic dust.

The severity of airway inflammation induced by organic dust is dose dependent in both control and RAO horses, and the threshold for induction of inflammation is far greater in the control group (29). The dose of dust suspension utilized in the present study was the highest dose administered to RAO horses by Pirie et al. (29). Three different hay dust suspensions

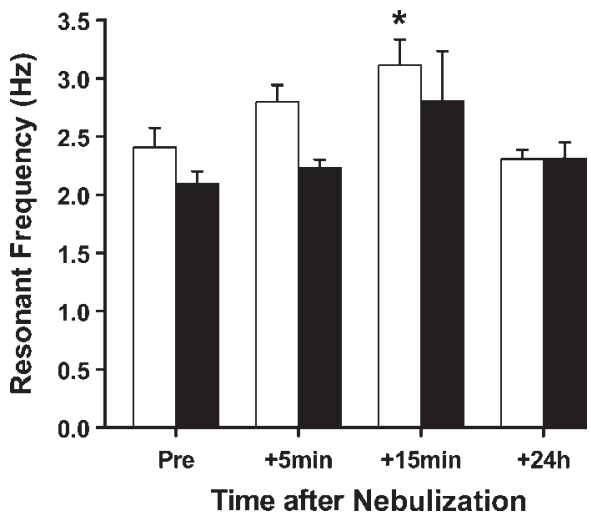

Fig. 4. Resonant frequency in control horses ( $n=6$; open bars) and horses affected by recurrent airway obstruction $(n=6$; closed bars) before (Pre) and after nebulization of organic dust. Data are means \pm SE. *Significantly different compared with Pre and $24 \mathrm{~h}$ post $(P \leq 0.025)$. induced marked airway inflammation in RAO horses when administered at the dose used in the present study (29). For BAL performed $24 \mathrm{~h}$ after nebulization, an adjacent airway was lavaged to that sampled $10 \mathrm{~min}$ after nebulization to minimize the effects of the previous BAL on BALF cytology. Sweeney et al. (37) demonstrated that any effects of a BAL on BALF cytology from an adjacent airway were eliminated within $48 \mathrm{~h}$. Repeating the BAL procedure after 6 and $24 \mathrm{~h}$ on different lung regions did not significantly alter BALF cytology in healthy horses (25). Similarly, in the present study, BALF neutrophil numbers were only significantly elevated in the RAO group and not in the control horses $24 \mathrm{~h}$ after

\section{Mast cell number (/ $\mu$ l BALF) Pre}

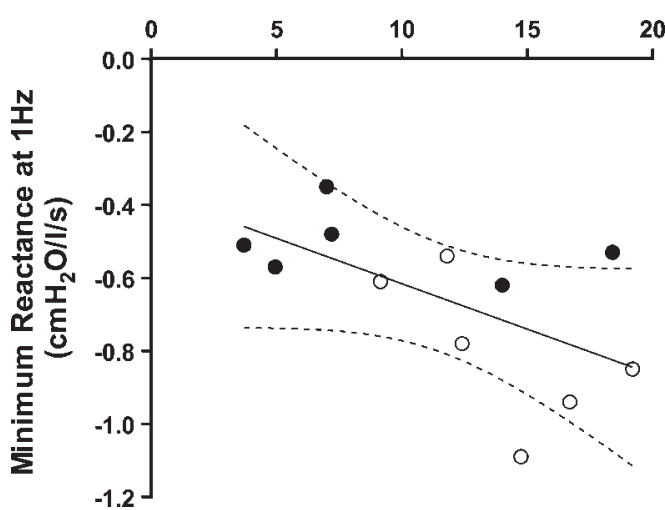

Fig. 5. Correlation between the number of mast cells in BALF before nebulization and minimum total respiratory reactance at $1 \mathrm{~Hz}$ either 5 or $10 \mathrm{~min}$ after nebulization of organic dust in control horses $(O)$ and horses affected by recurrent airway obstruction $(\bullet)(r=-0.65, P=0.02)$. 
nebulization and BAL of an adjacent airway. Therefore, the airway inflammation induced $24 \mathrm{~h}$ after nebulization in the RAO group is likely to have been induced by organic dust, in agreement with Pirie et al. (29).

The absence of a significant correlation between measures of lung dysfunction associated with the early-phase response and BALF neutrophil numbers $24 \mathrm{~h}$ postnebulization suggests that the lack of an early-phase airway obstruction is not the predominant factor in RAO-affected horses developing a latephase inflammatory response. However, the power of the study may have been insufficient to determine a significant correlation. In addition, the airway inflammation may have partially resolved by $24 \mathrm{~h}$ as neutrophil infiltration into the pulmonary epithelial lining fluid occurs within $6 \mathrm{~h}$ of organic dust nebulization in RAO horses (29). Inhaled dust may induce the late-phase neutrophilic infiltration in RAO observed in the present study by enhancing the production of proinflammatory mediators from a range of cell types in addition to mast cells, such as alveolar macrophages, lymphocytes, and airway epithelial cells $(6,7,24,41)$. Reduced numbers of macrophages and lymphocytes were evident in control horses immediately after challenge. This reduction was unanticipated, and we have no data to suggest a mechanism for such effects. The inflammatory process is likely to be complex, given the diverse composition of organic dust. Components of organic dust have synergistic effects on the development of airway inflammation when inhaled together $(30,31)$.

Another important component of the late-phase response in RAO is the induction of reversible airway obstruction. However, in the present study, increases in resistance and decreases in reactance were not detected $24 \mathrm{~h}$ after nebulization compared with baseline measurements in either RAO or control horses. Similarly Pirie et al. (29) determined that dynamic lung compliance, maximum change in transpulmonary pressure, and a clinical score of respiratory effort were not altered in RAO horses $5 \mathrm{~h}$ after nebulization of hay dust suspension. These findings are likely to reflect the short duration of the challenge compared with continuous exposure to organic dust by stabling with hay and straw. Horses were exposed to organic dust by nebulization of a hay-straw dust suspension rather than stabling with hay and straw so that the dose of organic dust that each horse received could be standardized. To confirm that the early-phase response in control horses has a protective effect on lung function, horses would have to be exposed to organic dust after the induction of the early-phase response.

In conclusion, exposure to organic dust results in a mild early-phase airway obstruction in healthy horses but not in horses affected by RAO. This early-phase response appears to be regulated by mast cell-derived mediators and may be a protective mechanism to decrease the dose of organic dust reaching the peripheral airways.

\section{ACKNOWLEDGMENTS}

We are grateful to Kevin McMahon for technical support.

Present address for D. Marlin: Equine Sports Medicine Centre, University of Bristol, Langford, N. Somerset, UK.

\section{REFERENCES}

1. Ali H, Panettieri RA Jr. Anaphylatoxin C3a receptors in asthma. Respir Res 6: 19, 2005.
2. Anton F, Leverkoehne I, Mundhenk L, Thoreson WB, Gruber AD. Overexpression of eCLCA1 in small airways of horses with recurrent airway obstruction. J Histochem Cytochem 53: 1011-1021, 2005.

3. Bautsch W, Hoymann HG, Zhang Q, Meier-Wiedenbach I, Raschke U, Ames RS, Sohns B, Flemme N, Meyer zu Vilsendorf A, Grove M, Klos A, Kohl J. Cutting edge: guinea pigs with a natural C3a-receptor defect exhibit decreased bronchoconstriction in allergic airway disease: evidence for an involvement of the $\mathrm{C} 3 \mathrm{a}$ anaphylatoxin in the pathogenesis of asthma. J Immunol 165: 5401-5405, 2000.

4. Bingham CO, 3rd, Austen KF. Mast-cell responses in the development of asthma. J Allergy Clin Immunol 105: S527-534, 2000.

5. Broadstone RV, Gray PR, Robinson NE, Derksen FJ. Effects of xylazine on airway function in ponies with recurrent airway obstruction. Am J Vet Res 53: 1813-1817, 1992.

6. Bureau F, Bonizzi G, Kirschvink N, Delhalle S, Desmecht D, Merville MP, Bours V, Lekeux P. Correlation between nuclear factor- $\kappa \mathrm{B}$ activity in bronchial brushing samples and lung dysfunction in an animal model of asthma. Am J Respir Crit Care Med 161: 1314-1321, 2000.

7. Cordeau ME, Joubert P, Dewachi O, Hamid Q, Lavoie JP. IL-4, IL-5 and IFN- $\gamma$ mRNA expression in pulmonary lymphocytes in equine heaves. Vet Immunol Immunopathol 97: 87-96, 2004.

8. D'Amato G. Role of anti-IgE monoclonal antibody (omalizumab) in the treatment of bronchial asthma and allergic respiratory diseases. Eur J Pharmacol 533: 302-307, 2006.

9. D'Amato G, Liccardi G, Noschese P, Salzillo A, D'Amato M, Cazzola M. Anti-IgE monoclonal antibody (omalizumab) in the treatment of atopic asthma and allergic respiratory diseases. Curr Drug Targets Inflamm Allergy 3: 227-229, 2004.

10. Deaton CM, Marlin DJ, Roberts CA, Smith N, Harris PA, Kelly FJ, Schroter RC. Antioxidant supplementation and pulmonary function at rest and exercise. Equine Vet J Suppl 34: 58-65, 2002.

11. Deaton CM, Marlin DJ, Smith NC, Harris PA, Dagleish MP, Schroter RC, Kelly FJ. Effect of acute airway inflammation on the pulmonary antioxidant status. Exp Lung Res 31: 653-670, 2005.

12. Dente FL, Carnevali S, Paggiaro PL, Cianchetti S, Bacci E, Bancalari L, Di Franco A, Giannini D, Vagaggini B, Giuntini C. Relationship between serum heat-stable neutrophil chemotactic activity during early airway reaction to allergen and the pattern of airway response (early vs. late reactions) in asthmatic subjects. Respiration 64: 285-290, 1997.

13. Dirscherl P, Grabner A, Buschmann H. Responsiveness of basophil granulocytes of horses suffering from chronic obstructive pulmonary disease to various allergens. Vet Immunol Immunopathol 38: 217-227, 1993.

14. Galli SJ, Costa JJ. Mast-cell-leukocyte cytokine cascades in allergic inflammation. Allergy 50: 851-862, 1995.

15. Giguère S, Viel L, Lee E, MacKay RJ, Hernandez J, Franchini M. Cytokine induction in pulmonary airways of horses with heaves and effect of therapy with inhaled fluticasone propionate. Vet Immunol Immunopathol 85: 147-158, 2002.

16. Gilfillan AM, Tkaczyk C. Integrated signalling pathways for mast-cell activation. Nat Rev Immunol 6: 218-230, 2006.

17. Gray PR, Derksen FJ, Broadstone RV, Robinson NE, Peters-Golden M. Decreased airway mucosal prostaglandin $\mathrm{E}_{2}$ production during airway obstruction in an animal model of asthma. Am Rev Respir Dis 146: 586-591, 1992.

18. Halliwell RE, McGorum BC, Irving P, Dixon PM. Local and systemic antibody production in horses affected with chronic obstructive pulmonary disease. Vet Immunol Immunopathol 38: 201-215, 1993.

19. Hare JE, Viel L, Conlon PD, Marshall JS. In vitro allergen-induced degranulation of pulmonary mast cells from horses with recurrent airway obstruction (heaves). Am J Vet Res 60: 841-847, 1999.

20. Horohov DW, Beadle RE, Mouch S, Pourciau SS. Temporal regulation of cytokine mRNA expression in equine recurrent airway obstruction. Vet Immunol Immunopathol 108: 237-245, 2005.

21. Hundley TR, Gilfillan AM, Tkaczyk C, Andrade MV, Metcalfe DD, Beaven MA. Kit and FceRI mediate unique and convergent signals for release of inflammatory mediators from human mast cells. Blood 104: 2410-2417, 2004.

22. Ignesti G, Banchelli G, Raimondi L, Pirisino R, Buffoni F. Histaminase activity in rat lung and its comparison with intestinal mucosal diamine oxidase. Agents Actions 35: 192-199, 1992.

23. Krishna MT, Chauhan A, Little L, Sampson K, Hawksworth R, Mant T, Djukanovic R, Lee T, Holgate S. Inhibition of mast cell tryptase by 
inhaled APC 366 attenuates allergen-induced late-phase airway obstruction in asthma. J Allergy Clin Immunol 107: 1039-1045, 2001.

24. Laan TT, Bull S, Pirie R, Fink-Gremmels J. The role of alveolar macrophages in the pathogenesis of recurrent airway obstruction in horses. J Vet Intern Med 20: 167-174, 2006.

25. Lindberg A, Robinson NE, Nasman-Glaser B, Jensen-Waern M, Lindgren JA. Assessment of leukotriene B4 production in leukocytes from horses with recurrent airway obstruction. Am J Vet Res 65: 289-295, 2004.

26. McGorum BC, Dixon PM, Halliwell RE. Quantification of histamine in plasma and pulmonary fluids from horses with chronic obstructive pulmonary disease, before and after "natural (hay and straw) challenges." Vet Immunol Immunopathol 36: 223-237, 1993.

27. Metzger WJ, Zavala D, Richerson HB, Moseley P, Iwamota P, Monick M, Sjoerdsma K, Hunninghake GW. Local allergen challenge and bronchoalveolar lavage of allergic asthmatic lungs. Description of the model and local airway inflammation. Am Rev Respir Dis 135: 433-440, 1987.

28. Olszewski MA, Robinson NE, Zhu FX, Zhang XY, Tithof PK. Mediators of anaphylaxis but not activated neutrophils augment cholinergic responses of equine small airways. Am J Physiol Lung Cell Mol Physiol 276: L522-L529, 1999.

29. Pirie RS, Collie DD, Dixon PM, McGorum BC. Evaluation of nebulised hay dust suspensions (HDS) for the diagnosis and investigation of heaves. 2. Effects of inhaled HDS on control and heaves horses. Equine Vet $J 34$ : 337-342, 2002.

30. Pirie RS, Collie DD, Dixon PM, McGorum BC. Inhaled endotoxin and organic dust particulates have synergistic proinflammatory effects in equine heaves (organic dust-induced asthma). Clin Exp Allergy 33: 676683, 2003.

31. Pirie RS, Dixon PM, McGorum BC. Evaluation of nebulised hay dust suspensions (HDS) for the diagnosis and investigation of heaves. 3. Effect of fractionation of HDS. Equine Vet J 34: 343-347, 2002.

32. Pirie RS, McLachlan G, McGorum BC. Evaluation of nebulised hay dust suspensions (HDS) for the diagnosis and investigation of heaves. 1 . Preparation and composition of HDS. Equine Vet J 34: 332-336, 2002.
33. Schmallenbach KH, Rahman I, Sasse HH, Dixon PM, Halliwell RE, McGorum BC, Crameri R, Miller HR. Studies on pulmonary and systemic Aspergillus fumigatus-specific $\operatorname{IgE}$ and $\operatorname{IgG}$ antibodies in horses affected with chronic obstructive pulmonary disease (COPD). Vet Iттиnol Immunopathol 66: 245-256, 1998.

34. Smith HJ, Reinhold P, Goldman MD. Forced oscillation technique and impulse oscillometry. In: European Respiratory Monograph, edited by Gosselink R and Stam H. Sheffield: ERS Journals, 2005, p. 72-105.

35. Snapper JR. Large animal models of asthma. Am Rev Respir Dis 133: 351-352, 1986.

36. Svartengren M, Philipson K, Camner P. Individual differences in regional deposition of 6-micron particles in humans with induced bronchoconstriction. Exp Lung Res 15: 139-149, 1989.

37. Sweeney CR, Rossier Y, Ziemer EL, Lindborg SR. Effect of prior lavage on bronchoalveolar lavage fluid cell population of lavaged and unlavaged lung segments in horses. Am J Vet Res 55: 1501-1504, 1994.

38. Tohda Y, Kubo H, Ito M, Fukuoka M, Nakajima S. Histopathology of the airway epithelium in an experimental dual-phase model of bronchial asthma. Clin Exp Allergy 31: 135-143, 2001.

39. Turlej RK, Fievez L, Sandersen CF, Dogne S, Kirschvink N, Lekeux $\mathbf{P}$, Bureau F. Enhanced survival of lung granulocytes in an animal model of asthma: evidence for a role of GM-CSF activated STAT5 signalling pathway. Thorax 56: 696-702, 2001.

40. Turner H, Kinet JP. Signalling through the high-affinity IgE receptor FceRI. Nature 402: B24-B30, 1999.

41. Van der Haegen A, Kunzle F, Gerber V, Welle M, Robinson NE, Marti E. Mast cells and IgE-bearing cells in lungs of RAO-affected horses. Vet Immunol Immunopathol 108: 325-334, 2005.

42. Van der Kleij HP, Kraneveld AD, van Houwelingen AH, Kool M, Weitenberg AC, Redegeld FA, Nijkamp FP. Murine model for nonIgE-mediated asthma. Inflammation 28: 115-125, 2004.

43. Young SS, Tesarowski D. Respiratory mechanics of horses measured by conventional and forced oscillation techniques. J Appl Physiol 76: 24672472, 1994.

44. Young SS, Tesarowski D, Viel L. Frequency dependence of forced oscillatory respiratory mechanics in horses with heaves. J Appl Physiol 82: 983-987, 1997. 